\title{
A PROFESSORA E A INTERAÇÃO PESSOAL INFANTIL
}

Joyce Garbosa de Azevedo; Fabio Camargo Bandeira Villela

Universidade Estadual Paulista - UNESP, Curso de Pedagogia, Presidente Prudente, SP. E-ail: joyce98ga@hotmail.com Apoio Acadêmico e Extensão I - PROEX/UNESP

\section{RESUMO}

O artigo investiga a visão do psicanalista inglês Donald W. Winnicott acerca do desenvolvimento emocional infantil, a participação da mãe nesse processo e a importância de um ambiente externo que favoreça a criança nesse complexo desenvolvimento. Além disso, as falhas e as consequências que podem haver e o papel da professora na sala de aula frente às crianças que foram prejudicadas no decorrer do desenvolvimento maturacional do ego. A importância do ambiente externo tranquilo para que esse processo ocorra, bem como a socialização do indivíduo com os demais. A criança que não conseguiu desenvolver-se busca, a todo tempo, uma personalidade forte, capaz de lhe ajudar a reiniciar o processo de maturação e, assim, reestruturar sua personalidade de forma segura e tranquila.

Palavras-chave: ego, desenvolvimento emocional, psicanálise, professora, Winnicott.

\section{THE TEACHER AND THE PERSONAL CHILDREN INTERACTION}

\begin{abstract}
The article discusses the views of the English psychoanalyst Donald W Winnicott on the subject of emotional development in the infant, the mother's participation in this process and the importance of the external environment in favouring the child during this complex development. Failures, and what their consequences might be, are also discussed along with the role of the classroom teacher, faced with children who have been harmed during the maturational development of the ego. Consideration is also given to the importance of a peaceful external environment supporting this process, as well as the socialization of the individual child with his or her peers. The child who fails to develop looks for a person who has a strong personality, able to help him to restart the maturing process to restructure his personality in a secure and settled way. Keywords: ego, emotional development, psychoanalysis, teacher, Winnicott.
\end{abstract}




\section{INTRODUÇÃO}

A construção de uma personalidade sadia tem suas bases no desenvolvimento emocional infantil. Esse complexo processo, inicialmente, tem como principal figura a mãe, que, ao buscar uma adaptação ativa às necessidades da criança, Ihe incentiva a desencadear os processos maturacionais.

Quando a mãe não consegue uma adaptação ativa às necessidades do processo emocional, a criança tem obstruído seu desenvolvimento e pode sofrer um processo de desestruturação do EU. No caso de haver essa falha, é importante investigar se sua professora tem a possiblidade de intervir e ajudar a criança em seu desenvolvimento emocional e se é possível contribuir para a retomada do desenvolvimento emocional da criança.

O objetivo deste estudo é articular três temas presentes na obra de Winnicott: os processos que envolvem o desenvolvimento emocional infantil, as falhas que podem haver nesse processo e, com base nisso, as possibilidades de auxílio emocional que a professora pode prestar à criança dentro do espaço escolar nessas situações.

\section{METODOLOGIA}

A metodologia utilizada para a realização desse trabalho é a de ensaio, com base em bibliografia de Winnicott sobre os temas articulados. A contribuição da professora no processo de desenvolvimento emocional infantil com base na teoria de Donald W. Winnicott está discutida com referência à articulação entre a sua concepção de desenvolvimento infantil e o papel desempenhado pela mãe nesse processo. As possibilidades de intervenção da professora estão pensadas levando-se em conta sobretudo as eventuais dificuldades emocionais, principalmente relacionadas à perda - absoluta ou relativa - dos cuidados e do amor maternos destinados à criança. O caráter de ensaio do método refere-se à liberdade de articular temas presentes na obra de Winnicott, mas que não estão no autor articulados da forma intencional que assume o presente artigo. A referência a títulos de Winnicott será a tônica da fonte bibliográfica do presente artigo, portanto, dado que se busca uma compreensão interna à obra de Winnicott dos temas escolhidos e que se articulam como objeto do presente ensaio, não há nenhum propósito de confronto de sua teoria com outros referenciais teóricos.

\section{RESULTADOS}

Em linhas gerais, o desenvolvimento emocional do ser humano para Winnicott passa do estado de pura indiferenciação e ausência da consciência de si para a diferenciação, constituição e ampliação do self, consciência de si, localização da psique no corpo e capacidade de estabelecimento de relações com mais de uma pessoa total - que integre aspectos bons e ruins, bem como estados diversos da experiência do sujeito. Essa enorme transformação se dá ao longo do tempo e passa por etapas muito distintas. O modo como cada criança enfrenta e supera os desafios típicos de cada etapa forma uma personalidade única e lhe fornece recursos, bem como Ihe traz pontos fracos ou vulneráveis, para enfrentar os desafios e as vicissitudes típicas da fase seguinte. Em Winnicott, a etapa em que se encontra a criança é pouco fixa e comporta idas e vindas em relação às anteriores e mesmo uma participação simultânea em vários estágios (WINNICOTT, 1990, p. 52), mas se pode supor didaticamente, acompanhando Winnicott, um primeiro momento do desenvolvimento emocional em que o ser humano progressivamente é compelido a três desafios: a) estabelecer uma relação com a realidade externa, b) integrar o self a partir do estado de não integração e c) localizar a psique em seu corpo (WINNICOTT, 1990, p. 119).

Superada em grande parte essa primeira etapa, a criança começa a estabelecer uma distinção entre ela e o outro e a estabelecer com esse outro, em geral a mãe, uma relação de objeto total, integrando em uma única pessoa, externa ao sujeito, os aspectos bons e ruins, gratificantes ou frustrantes (WINNICOTT, 1990, p. 87). Um terceiro período importante seria a 
capacidade de estabelecer simultaneamente relações com mais de um objeto total, ao mesmo tempo a capacidade de buscar equacionar os conflitos dessas relações, o que basicamente configura o período do complexo de Édipo (WINNICOTT, 1990, p. 55).

O presente trabalho inicia-se com a discussão de aspectos específicos desse desenvolvimento emocional primitivo, dá destaque ao papel da mãe - ou quem a substitua em sua relação com a criança -, discute problemas graves e recorrentes dessa relação para, ao fim, localizar as possiblidades de atuação da professora no sentido de lidar com falhas no desenvolvimento emocional da criança, temas que passaremos a discutir.

As crianças que são favorecidas com um lar saudável e harmonioso podem mais facilmente ter um desenvolvimento emocional que lhes proporciona ir à escola em busca de novos conhecimentos. Além disso, através da interação, criam novos laços e os enriquecem. Em contrapartida, as crianças que não tem um lar suficientemente adaptado às suas necessidades, buscam reconstituir na escola algo próximo a uma família que Ihes ajude em suas necessidades emocionais. Nessas situações, a escola tem o papel de adaptar-se às crianças, proporcionando a elas um ambiente que supra, em parte, as suas necessidades. Isso requer professores que estejam preparados e dispostos a favorecer o desenvolvimento emocional das crianças.

Durante a vida do indivíduo, há um desenvolvimento constante, porém, para a criança, esse processo é bem mais complexo, devido à transição da dependência para a independência.

Nas fases iniciais, o bebê depende dos cuidados maternos. "Se a mãe não conseguir uma adaptação adequada às necessidades do bebê, ele não poderá evitar o desenvolvimento de defesas que distorcem o processo". (WINNICOTT, 2005, p. 217). Durante esse período, o bebê acredita que a mãe não se distingue dele, que faz parte dele e que foi criada exclusivamente por ele. Gradativamente, o bebê constrói a realidade externa com base em sua relação com a mãe, que sobrevive às suas intemperanças e ataques, constituindo o alicerce para uma boa saúde mental da criança.

Antes da integração, o indivíduo é inorganizado, inarticulado, mera coleção de fenômenos sensoriomotores, reunidos pelo ambiente suportador. Depois da integração, o indivíduo É, quer dizer, o ser humano infantil atingiu o status de unidade e pode dizer EU SOU. (WINNICOTT, 2005, p. 217)

Essa separação entre ambos, a apresentação externa e a maturação do ego, são processos longos e ocorrem de forma gradativa, por isso, é comum que, durante essa transição, persistam resíduos e a criança adote um objeto transicional, que lhe ajudará a tornar possível "o contato entre a psique individual e a realidade externa". (WINNICOTT, 2005, p. 219)

Há, portanto, situações falhas no ambiente que levam o ego a organizar defesas, que se manifestam como sintomas, que funcionam como resistências. O distúrbio de caráter "é uma distorção da estrutura do ego, sendo a integração, não obstante, mantida". (WINNICOTT, 2005, p. 276). Quando isso acontece, o indivíduo para seu processo de desenvolvimento emocional e passa a preocupar-se com os problemas do meio. Nesses casos, a criança sofre por precisar continuar o processo de maturação com o desenvolvimento emocional perturbado e, também, por manter uma esperança secreta que talvez não se cumpra e temer uma possível retaliação do meio, se seu pedido secreto e inconsciente de ajuda ocorre através de condutas antissociais, que costumam afligir os pais, professores e sociedade em geral.

Entre os 2 e 5 anos, a criança passa por penosos conflitos decorrentes das tensões geradas por suas relações com mais de uma pessoa total, tornando uma dessas alvo de sua rivalidade, que pode manifestar-se tanto na fantasia quanto na realidade. Essas fortes tendências instintivas enriquecem os sentimentos e as relações pessoais no futuro. Quando a criança passa por essa fase de conflitos, com a ajuda do meio que Ihe fornece confiança, ela começa a sentir-se culpada pelos 
danos causados e busca repará-los. Quando essa fase do desenvolvimento é turbulenta, surgem sintomas, que revelam a angústia da criança, sendo os mais notáveis as crises de mau humor, explosões maníacas, falta de interesse pela higiene e pelas roupas, comportamento excêntrico e insano, bem como enurese noturna e incontinência fecal.

A consequência desses acontecimentos é que às idéias de amor se seguem às idéias de ódio, o ciúme e um conflito emocional doloroso, enfim, o sofrimento pessoal; e sempre que o conflito é demasiado grande, sobrevêm a perda de capacidade total, inibições, "recalque" etc., resultando na formação de sintomas. (WINNICOTT, 2008, p. 217)

A criança que teve falhas no processo de desenvolvimento emocional mantém uma esperança viva e, por isso, testa continuamente o ambiente e as pessoas em busca de uma segurança que lhe permita recomeçar esse processo de forma saudável. A fim de sentir-se confiante e estabelecer uma relação com o meio, a criança precisa sentir-se livre, pois essa fase é marcada por conflitos intensos e que causam angústia na mesma. Sendo assim, a criança deve sentir uma segurança externa que the propicie soltar sua imaginação, a fim de progredir emocionalmente. Só a partir dessa estabilidade externa do ambiente a criança passará da dependência para a independência.

Quando o indivíduo torna-se capaz de interagir com o grupo e tem um desenvolvimento emocional saudável, há um enriquecimento, tanto ao grupo que é favorecido com sua individualidade, quanto para a criança que cresce socialmente. Segundo Winnicott, foi atingido "o estágio de uma unidade humana integrada". (2005, p. 219)

Há casos em que a criança não estabeleceu nenhuma relação confiável com os pais ou com qualquer outro indivíduo que estivesse disposto a ajudá-la a corrigir uma falha no desenvolvimento. Ela passa, então, a ofender a sociedade em busca de um controle externo mais rígido, que lhe proporcione segurança. Portanto, é essencial que a professora esteja atenta ao diferenciar uma criança com um grau normal de tendência antissocial, resultado do complexo processo de desenvolvimento emocional, de uma que está mais próxima da delinquência. Normalmente, a criança que apresenta uma tendência consolidada, busca acomodá-la, o que resultará em reações, tais como, dizer mentiras de maneira geral e sistemática, tornar-se arrogante, ou mesmo através de um distúrbio de caráter. Não obstante, o distúrbio de caráter ainda é um mecanismo de proteção da personalidade, ameaçada por perigo maior, representado pela desintegração psicótica.

É meu intuito chamar a atenção para o elemento positivo no distúrbio de caráter. Se o indivíduo não consegue adquirir um distúrbio de caráter, quando se esforça por acomodar um certo grau de tendência anti-social, então correrá o risco de colapso psicótico. O distúrbio de caráter indica que a estrutura do ego do indivíduo pode ligar as energias envolvidas na paralisação dos processos de amadurecimento e também as anormalidades na interação da criança e da família. Até que os ganhos secundários tenham se tornado uma característica, a personalidade com distúrbio de caráter está sempre correndo o risco de se desintegrar em paranóia, depressão maníaca, psicose ou esquizofrenia. (WINNICOTT, 2005, p. 284)

Depois da família, na maioria dos casos, a professora é quem mantém um contato mais próximo com a criança, e tem a possibilidade de ajudá-la na sala de aula, e, através da interação, resolver falhas que se desenvolveram como anormalidades. Sendo assim, além da família, a professora é a principal figura com a qual a criança tem a possibilidade de estabelecer vínculos 
confiáveis. À semelhança do proposto por Winnicott para os supervisores de alojamentos para crianças sem lar, é necessário que a professora busque "[...] proporcionar estabilidade, que as crianças pudessem conhecer, testar, em que aos poucos pudessem confiar...". (2005, p. 74)

Ainda em extensão ao disposto para os supervisores em alojamentos, a professora que estiver disposta a ajudar a criança, deverá observar se houve ou não a presença de um lar satisfatório e, quando possível, observar a relação entre mãe e filho e vice versa, o modo que um trata o outro, o jeito de conversar, ou seja, o comportamento entre ambos. A partir dessa observação, o ambiente da sala de aula e a professora poderão "fornecer alguma correção dessas anormalidades no decorrer do tempo e, gradualmente habilitar a criança a encarar objetivamente e até com indulgência, o seu próprio lar". (WINNICOTT, 2005, p. 72)

Mesmo que o ambiente escolar seja agradável, a professora dedicada, confiante e atenta às particularidades de cada aluno só conseguirá ajudar a reestruturar o desenvolvimento emocional até certo grau, pois a escola dificilmente suprirá as necessidades da criança como tende a ocorrer em um lar primário. Em busca de ajudar ao máximo a criança, a professora deverá aproveitar tudo o que tenha lhe restado de um bom lar.

A escola, entretanto, pode apresentar certas vantagens em relação à família para situações específicas de elaboração de conflito, pois a criança busca um ambiente que the proporcione estabilidade e seja seguro e agradável e não tão denso e definitivo como sua família e as relações que estabelecem: devido aos intensos conflitos internos, o lar torna-se um ambiente demasiado denso para o desenvolvimento pessoal infantil, o que leva a guardar certos sofrimentos ocultos que o ambiente escolar lhe permitiria aliviar a tensão, através dos jogos, das brincadeiras, da relação de amizade com os demais, etc. Portanto, é necessário que a professora busque entender a natureza desse processo e as reações que são provocadas pelos conflitos emocionais.

Esse aspecto [lidar de modo autêntico e espontâneo com os acontecimentos e as relações. - JGA] é extremamente importante, pois somente aqueles que são suficientemente confiantes para serem eles mesmos, e para agirem de um modo natural, podem atuar coerentemente todos os dias. Além disso, os superiores são submetidos a uma prova tão severa pelas crianças, que só os que são capazes de serem sempre eles mesmos conseguem suportar a tensão. (WINNICOTT, 2005, p. 76)

Quando o ambiente é seguro e a criança encontra na professora uma estrutura forte, inicia-se o processo de reestruturação e integração do indivíduo, ou seja, a maturação normal do ego, que será a estrutura para a formação da personalidade. Durante este processo, a criança passa pela transferência, sem a qual não poderia haver nova integração, este processo lhe permite regredir ao estado que o desenvolvimento emocional foi afetado.

A reprodução, no tratamento, de exemplos resultantes do fracasso ambiental original, somada à experiência de raiva apropriada do paciente, liberta os processos maturacionais do paciente; é preciso lembrar que este se encontra num estado de dependência e tem necessidade de apoio ao ego e de administração ambiental (segurança) no contexto de tratamento, e a fase seguinte precisa ser um período de crescimento emocional em que o caráter se constrói positivamente e perde suas distorções. (WINNICOTT, 2005, p. 283)

Com a regressão da criança ao ponto da maturação que lhe foi falho, ela revive a situação junto com a professora, que certamente, passará por situações difíceis e, se realmente estiver disposta a ajudar a criança, deverá suportá-la e dar-lhe cobertura, até que haja a integração 
pessoal. Por sorte, este processo é tolerável, pelo fato de que nem todas as crianças atingirão o ponto mais baixo da não integração de uma só vez.

Concluímos que a criança que teve um lar tranquilo e harmonioso, com pais presentes, atentos e carinhosos, reúne condições bastante favoráveis para um desenvolvimento emocional saudável, ainda que não isento dos conflitos e sofrimentos que lhe são comuns. Algumas crianças não apresentam essas condições e nem conseguiram alcançar um desenvolvimento emocional saudável, o que, em muitos casos, pode conseguir restabelecer um curso mais saudável de seu desenvolvimento emocional com a ajuda de uma pessoa com a personalidade forte e confiante, que, na maioria das vezes, é a professora. Em um ambiente escolar equilibrado, cada uma dessas crianças pode desenvolver-se e ter a chance de reestruturar o ego, tornando-se um adulto responsável e autônomo.

\section{DISCUSSÃO}

Segundo Winnicott, a criança é uma "organização em marcha", devido aos intensos processos que envolvem o desenvolvimento infantil. $O$ bebê, inicialmente, depende totalmente dos cuidados maternos e, como não há uma integração da personalidade, a mãe do bebê recémnascido tende a se adaptar rapidamente às suas necessidades, fornecendo-lhe cuidados apropriados frente a elas. Para ele, a mãe não passa de alguém criado exclusivamente por sua imaginação, até que seu amadurecimento e sua maior confiança permita à mãe uma progressiva desadaptação frente às necessidades e solicitações de seu bebê, o que acaba propiciando uma maior autonomia do bebê que fora bem atendido pela mãe em seus primeiros meses de vida.

Nessa fase do desenvolvimento, quando a criança começa a reconhecer e, aos poucos, a aceitar a realidade externa, tem curso uma integração de sua personalidade. Para que esse processo ocorra da melhor forma possível, é essencial que a criança sinta-se segura, ou seja, que haja uma estabilidade externa, que os efeitos dos bons cuidados tenha ampliado a confiança que tem em si própria e na capacidade de ser atendida e de sobreviver às dificuldades momentâneas que enfrenta. No entanto, pode haver falhas graves no decorrer desse processo, que, se não corrigidas, provocam um grande dano em seu desenvolvimento.

A criança que teve falhas nesse processo de amadurecimento poderá ter a possibilidade de reestruturar-se no ambiente escolar, quando a professora é atenta, observa as particularidades de cada criança e consegue dispensar um olhar e um cuidado em certo sentido especiais à criança $\mathrm{e}$ que, sobretudo, sobreviva emocionalmente às dificuldades e eventuais ataques oriundos dessa criança com problemas emocionais. O estabelecimento de relações confiáveis e estáveis com a criança tende a ajudá-la a regressar ao ponto em que foi prejudicada e reiniciar esse processo de maturação do ego, o que corrigirá, até certo ponto, algumas deficiências do desenvolvimento emocional.

\section{CONCLUSÃO}

O desenvolvimento emocional infantil é favorecido quando o lar é tranquilo, harmonioso e que oferece à criança condições emocionais adequadas. Devido à complexidade do desenvolvimento, sempre há conflitos e sofrimento emocional da criança. As crianças que não tiveram o mínimo para que esse desenvolvimento ocorra de forma tranquila buscam assiduamente alguém que Ihe proporcione estabilidade e Ihe ajude a se reestruturar. Em muitos casos, a professora acaba desempenhando um papel importante para dar segurança à criança e ser objeto de um importante vínculo afetivo, ainda que isso ocorra no contexto pedagógico e no espaço e da sala de aula. 


\section{REFERÊNCIAS}

WINNICOTT, W. A criança e o seu mundo. 6. ed. Rio de Janeiro: Zahar, 2008.

WINNICOTT, W. Natureza humana. S. ed. 6. ed. Rio de Janeiro: Imago, 1990.

WINNICOTT, W. Privação e Delinquência. 4. ed. São Paulo: Martins Fontes, 2005. 